Int. J. Electrochem. Sci., 15 (2020) 8928 - 8942

\title{
Hydrogen Evolution Inorganic Inhibitors in Alkaline Electrolyte for Aluminum-Air Battery
}

\author{
Seok-Ryul Choi ${ }^{\S}$, Sol-Ji Song ${ }^{\S}$, Jung-Gu Kim* \\ Department of Materials Science and Engineering, Sungkyunkwan University, 2066, Seobu-Ro, \\ Jangan-Gu, Suwon-Si, Republic of Korea, 16419 \\ ${ }^{\S}$ S.-R. Choi and S.-J. Song contributed equally to this work \\ "E-mail: kimjg@ @kku.edu
}

doi: $10.20964 / 2020.09 .65$

Received: 14 April 2020 / Accepted: 3 July 2020 / Published: 10 August 2020

\begin{abstract}
Arsenic oxide (As(III)), sodium phosphate monobasic anhydrous $\left(\mathrm{H}_{2} \mathrm{PO}_{4}^{-}\right)$, and antimony trioxide $(\mathrm{Sb}(\mathrm{III}))$ are used as electrolyte additives in $4 \mathrm{M}$ sodium hydroxide $(\mathrm{NaOH})$ electrolyte for Al-air batteries. The effects of inorganic additives are examined through hydrogen evolution and selfcorrosion testing, electrochemical analysis, and surface analysis. Electrochemical tests show that the presence of the additives lowers the hydrogen gas evolution rate and inhibits the adsorption of hydrogen on the aluminum surface. The additives in order of effectiveness are: $\mathrm{Sb}$ (III) > As(III) > $\mathrm{H}_{2} \mathrm{PO}_{4}{ }^{-}$. The addition of additives decreases the self-corrosion of $4 \mathrm{~N} \mathrm{Al}$, which improves the efficiency of the Al-air battery. The additives are confirmed as effective inhibitors of the hydrogen generation reaction in Al-air batteries.
\end{abstract}

Keywords: Aluminum-air battery ' Hydrogen evolution ' Inhibitor ' Battery efficiency · Electrochemical test

\section{$\underline{\text { FULL TEXT }}$}

(C) 2020 The Authors. Published by ESG (www.electrochemsci.org). This article is an open access article distributed under the terms and conditions of the Creative Commons Attribution license (http://creativecommons.org/licenses/by/4.0/). 